\title{
Learners' Factors in L2 Reading Comprehension
}

\author{
Afsane Askari \\ Dept. of Language, Azad University of Bandar Abbas \\ E-mail: afsane.askari2015@gmail.com \\ Hooshang Khoshsima (Corresponding author) \\ Dept. of Language, Chabahar Maritime University \\ E-mail:khoshsima2002@yahoo.com \\ Omid Khatin-Zadeh \\ Dept. of Language, Chabahar Maritime University \\ E-mail: Khatinzadeh.omid@yahoo.com \\ Hassan Banaruee \\ Dept. of Language, Chabahar Maritime University \\ E-mail: Hassan.banaruee@gmail.com
}

Received: September 2, 2017 Accepted: October 10, 2017 Published: October 20, 2017

doi:10.5296/gjes.v3i2.11797

URL: https://doi.org/10.5296/gjes.v3i2.11797

\begin{abstract}
Due to the existence of contrastive psychological and biological factors, learning processes vary from person to person. The awareness of the fact that dissimilarity exists among learners' preferences in learning, determines teachers to accommodate learners needs accordingly. This study aimed to investigate the correlation between learning styles and reading performance of candidates who attended Teacher Recruitment Test in Iran Language Institute. Participants of the study were classified into either failed-group or succeeded-group. To achieve the objective of the study, Ehrman and Leaver's Questionnaire (2003) was administered to the candidates. Then each participant was included in one of the two groups of ectenic or synoptic learners. Pearson Product Moment Correlation Coefficient was calculated to find any significant correlation between participants' scores in the reading tasks
\end{abstract}




\section{Macrothink}

Global Journal of Educational Studies

ISSN 2377-3936

and their scores as an ectenic L2 learner or a synoptic L2 learner. The obtained value of $\mathrm{R}$ was 0.77 , which is statistically significant and indicates that synoptic candidates were notably more successful than ectenic candidates in the reading tasks. While synoptic scores were positively correlated with participants' scores in reading tasks, ectenic scores were negatively correlated with participants' scores in the test. It was concluded that there is a significant correlation between learning styles and degree of success in reading tasks. A classification of successful learners at reading tests was consequently provided.

Keywords: Reading, Learning Styles, Ectenic, Synoptic, Field Independent, Learners' factors 


\section{Introduction}

In the field of language teaching, researchers are interested in investigating any correlation between learning styles and students' development in different features. Normally, educators teach as they have been prepared to teach. In accordance with any factors, this teaching arrangement could be performed in different ways; as students' and teachers' proficiency, academic background, curriculum design available, teaching techniques and strategies or learning styles and strategies (Ehrman, Leaver, \& Oxford, 2003). Comprehending the correlation with learners' language proficiency and learning styles could be essential for teachers (Zare-Behtash et al., 2017). In the event that is found the students' learning styles may particularly correspond with their success in academic tests, this also may affect the profession choices they might make later, along with reading is the most significant part of every evaluation. As well, in some situations these learners prefer to have scholastic challenges and fixed goals for academic examinations. Since then, reading comprehension as the most considerable source of knowledge has been one of the consequential parts in second language examinations.

Extensive research administered by educational teachers and psychologists have demonstrated that learning procedures differ from person to person due to the existence of psychological and biological variation (Khatin-Zadeh et al., 2017). Khoshsima and Banaruee (2017) declared that all of the students have personal characteristics associated with their learning processes and they may indicate the type of errors learners confront in the learning process. Moreover, Pask (1988) asserted that more than three-fifth of an individual's learning style is biologically urged.

For the reason that learning styles have a crucial role in the learning procedure, is of prime importance which the teachers do not disregard it. According to Dorneyei and Skehan (2005), at any time that educators informed about that different students learn disparately, they will control learners' learning styles and appropriately accommodate their necessities. In addition, being aware of the fact that learning styles and their roles might be of an eminent importance for researchers, educators, curriculum designers and even psychologists is beneficial. Banaruee, Khoshsima and Askari (2017) found that the learning style and preference of a learner is as important as the personality traits the learners have, and in language classrooms employ crucial roles, in a way that even the corrective feedback provided must be matched well with these preferences and styles. Furthermore, it is vital for job seekers and students in advanced levels to recognize how learning styles affect their performance on reading in examination. Learning styles are one of the notions that are assumed by investigators to indicate students' differences and needs. Consequently, the current research aimed to investigate the relationship between learning styles and reading performance of the candidates in Iran.

\section{Review of the Related Literature}

The related literature in this study has demonstrated that by being aware of how you learn, you can become a more productive and impressive student. It seems that only scholars shown any enthusiasm in finding correlations between learning styles and reading tasks results. Thus, 
this research is aimed to provide the enrichment of the present literature. A study done by Kolb and Kolb (2015) expressed the role of learner differences as indicator of the learning process they preferred to take while learning. Additionally, they found that in selecting a learning style, learners are influenced by their experiences and the environment. As a result, for teachers to supply teaching analysis that are accustomed with the learners' learning styles in order and initiate their students' learning styles in order to attain a desired learning style would be more appropriate. Reading comprehension is introduced as the process of cracking meaning from context. Actually each learner has specific performance in various language skills that determined Naiman et al. (1978) to highlight the concept "Good Language learner" to manifest learners' features in successful language learning. Zare-Behtash, Khatinzadeh and Banaruee (2017) concluded that reading is the most fundamental material in ESP courses in Iran and enjoys various teaching methodologies in classes which the role of learners learning preferences should be taken into account.

Lie and Qin's (2006) research strongly asserted that learning styles play a crucial role in student's learning strategy choices. In their study, the comparison between high and low achievers demonstrates that in practicing strategies which are not normally companioned with learners' preferred learning styles, high achievers are more efficient. Low achievers utilized maximum range of strategies. Therefore, the results revealed that there is remarkable difference between learning strategy use and language skills levels. Nevertheless, other researchers' foundations did not prop this point of view. For example, Kilic and Karadeniz (2004) scrutinized the effect of gender, navigation strategies and learning styles of the students on their progress. Their study demonstrated that learners' progress did not replace with navigation strategies, gender and learning styles. As well, it had been stated that navigation strategies did not remarkably contrast with gender and learning styles.

Felder (2010) also established that many learners have benefited from learning process about how their learning and learning models and differed from those of their classmates. For that purpose, in order to make learning procedure more effective and meaningful it is so important that learners be inform of their learning styles and teachers must also provide their teaching styles to the students' need so that the most favorable results from the teaching could be attained. This tailored teaching to the learners' learning styles have been highlighted in studies (Ehrman \& Oxford, 1990; Banaruee, 2016; Banaruee \& Askari, 2016) which claim providing corrective feedbacks preferred by the learners' learning styles must be in prominent considerations.

In the present literature the theorists described learning styles by taking various features into consideration. Zare-Behtash and Banaruee (2017) argued that textbook reading activities must enjoy a great variety to serve as many learning preferences and styles as possible. The difference between models and descriptions are the results of the fact that learning is gained at different aspects (Banaruee, Mohammadian \& Zare-Behtash, 2017). In the present study the efficacy of learning styles on L2 reading task performance results and their possible correlation is investigated and discussed. 


\section{Methodology}

This study was the quantitative research with a one shut case design. Participants included of thirty candidates for Iran Language Institute in Bandar Abbas, Iran. Fifteen participants were currently employed, and already taken the recruitment test at different times and fifteen participants were chosen non-randomly from the failures, who failed the teacher recruitment test administered by the institute in the winter of 2017. All the participants took a TOFEL PBT test as the recruitment exam. The aim was to investigate the possible correlation between learning styles and performance on reading tasks among Iranian teaching candidates. The focus of this study was to supply a better understanding of is there a correlation between teaching candidates' learning styles and their reading performance? And what types of learning styles are the most relevant ones to the rate of success in Iranian teaching candidates reading performance? This is so crucial to classify the learners by their preferences and their ability to succeed at reading performance.

\subsection{Participants}

The participants of this study were thirty Iranian EFL teachers, selected based on convenience sampling. Fifteen of the participants had passed the recruitment exam and were teaching at Iran Language Institute in Bandar Abbas and the rest had failed to pass the recruitment exam in the winter of 2017. All of the participants took the same TOFEL PBT.

\subsection{Instruments}

The instruments used in this study were TOFEL BPT test used by ILI as a recruitment test and E\&L questionnaire to investigate the participants' learning styles. The recruitment test consisted of five sections, including; vocabulary, listening, reading, grammar and cloze test, which reading was considered in this study. Each part was assigned 100 scores. And the candidates who scored 250 out of 500 were accepted to be recruited as teachers. The questionnaire chosen for this study was Ehrman and Leaver's Questionnaire (2003) which considers what is traditionally known as cognitive learner preferences as opposite poles of scale variable. The pairs of opposite called synoptic and ectenic poles comprising super-ordinates construct in this questionnaire. The questionnaire included thirty pairs of preferences for each of the ten variables. The computed scores will then favor one of the two opposite poles unless it happens to be placed in the middle of two. The ten pairs opposites are; field independent vs. field dependent, random vs. sequential, field sensitive vs. field insensitive, global vs. particular, impulsive vs. reflective, inductive vs. deductive, synthetic vs. analytic, analogue vs. digital, concrete vs. abstract and leveling vs. sharpening (Ehrman \& Leaver, 2003).

\subsection{Data Collection Procedures}

In this study initially E\&L questionnaires were given to the present teachers at Iran Language Institute. They were considered homogeneous since they had already taken the recruitment tests and their scores achieved on the recruitment test were present by the administrative office. Subsequently, after the results of the recruitment examination were made available by the administrative office. The fifteen randomly chosen candidates did not have passed the 


\section{Macrothink}

Global Journal of Educational Studies

ISSN 2377-3936

2017, Vol. 3, No. 2

exam received E\&L questionnaires. According to the information gathered the questionnaire the participants were grouped into ectenic and synoptic learners. Moreover, in this study based on the five segments of recruitment examination the reading part is highlighted and under the analysis.

\subsection{Data Analysis}

For the purpose of answering questions proposed by this research, the recruitment examination results were analyzed by categorizing and enumerating the scores out of 100 . The collected data from the questionnaire were qualitative as identified 10 subtypes of learning styles under an ecteno-synoptic spectrum. In order to make the results from the questionnaire quantitative, the ecteno-synoptic continuum was clarified and scored out of 10 . For example if a candidate enjoyed three synoptic styles, he/she would receive three scores and if a candidate enjoyed three ectenic styles, he/she would receive seven scores as the synoptism is the yardstick in this analysis. At the ultimate stage of the research, a test of Pearson Correlation Coefficient was provided in order to find possible correlation between the ecteno-synoptic range and the scores achieved on the reading tasks. Moreover, based on the frequency of occurrence, the most common learning styles among Iranian EFL learners were classified hierarchically.

\section{Results}

The results in table (1) below shows that Ectenic learners performed poorly and failed at the exam, only one of the failed candidates was a synoptic learner who achieved higher scores than the other ectenic learners comparatively. And only two of the failed candidates were ecteno-synptic, which makes the analysis more interesting and significant. The highest score gained by the candidates was 70 and the lowest one was 30 . The table illustrated below provides information regarding the specific learning style learners possessed, derived from the analysis of Ehrman and Leaver (2003) questionnaire. 


\section{MInstitute Macrothink $^{\text {Int }}$}

Table1. Teaching candidates failed at entering at iran language institute

\begin{tabular}{|c|c|c|c|c|c|c|c|c|c|c|c|c|c|c|c|c|c|c|c|c|c|c|c|c|}
\hline 匥 & \multicolumn{22}{|c|}{ Learning Styles } & \multirow{2}{*}{ 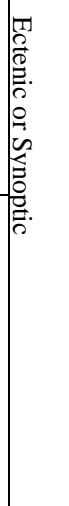 } & \\
\hline & 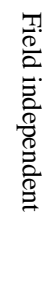 & $\begin{array}{l}\frac{7}{0} \\
\frac{0}{2} \\
\frac{0}{8} \\
\frac{0}{0} \\
0 \\
0 \\
0\end{array}$ & 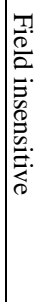 & 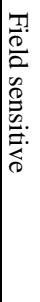 & 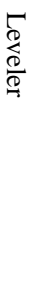 & 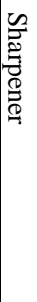 & | & 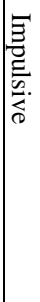 & 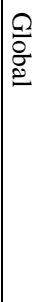 & 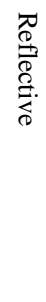 & 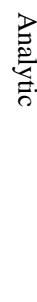 & 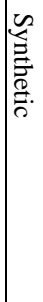 & . & 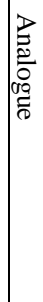 & 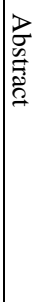 & ठ & 施 & & 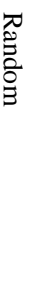 & 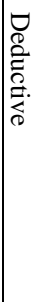 & 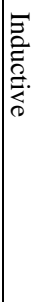 & 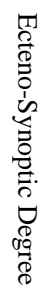 & & $\begin{array}{l}\tilde{\Omega} \\
\vdots \\
\varnothing \\
\infty\end{array}$ \\
\hline 1 & 0 & & & 0 & 0 & & & & 0 & 0 & & 0 & & 0 & & & & & 0 & 0 & & 6 & $\mathrm{~S}$ & 70 \\
\hline 2 & & 0 & 0 & & & 0 & 0 & & & 0 & 0 & & 0 & & 0 & . & & & & 0 & & 4 & E & 60 \\
\hline 3 & & 0 & 0 & & & 0 & 0 & 0 & . & & 0 & . & & 0 & 0 & & & & & 0 & & 3 & $\mathrm{E}$ & 50 \\
\hline 4 & & 0 & 0 & & & 0 & & 0 & 0 & & 0 & & 0 & & 0 & & & & & 0 & & 2 & $\mathrm{E}$ & 30 \\
\hline 5 & & 0 & 0 & & & 0 & 0 & 0 & & & 0 & & 0 & & 0 & & & & & 0 & & 4 & $\mathrm{E}$ & 30 \\
\hline 6 & & 0 & 0 & & 0 & & 0 & & & 0 & 0 & & 0 & & 0 & & & & 0 & & 0 & 3 & $\mathrm{E}$ & 40 \\
\hline 7 & & 0 & 0 & & & 0 & 0 & 0 & & & 0 & & 0 & & & & & & & 0 & & 4 & $\mathrm{E}$ & 40 \\
\hline 8 & 0 & & 0 & & & 0 & 0 & 0 & & & & 0 & & 0 & & & & & & 0 & & 4 & E & 30 \\
\hline 9 & & 0 & 0 & & 0 & & 0 & & 0 & 0 & 0 & & & 0 & 0 & & & & & 0 & & 3 & E & 50 \\
\hline 10 & & 0 & 0 & & & 0 & 0 & 0 & & & 0 & & & 0 & 0 & & & & & 0 & & 3 & E & 40 \\
\hline 11 & 0 & & & 0 & & 0 & & 0 & 0 & & 0 & & & 0 & & & & & & 0 & & 5 & ES & 50 \\
\hline 12 & & 0 & 0 & & & 0 & 0 & 0 & & & 0 & & 0 & & 0 & & & & & 0 & & 4 & E & 40 \\
\hline 13 & 0 & & & 0 & & 0 & & 0 & 0 & & 0 & & & 0 & & & & & & & 0 & 6 & $S$ & 60 \\
\hline 14 & & 0 & 0 & & & 0 & 0 & 0 & & & 0 & & 0 & & & & & & & 0 & & 4 & $\mathrm{E}$ & 50 \\
\hline 15 & 0 & & 0 & & & 0 & & 0 & & 0 & 0 & & 0 & & & & & & & 0 & & 4 & E & 60 \\
\hline
\end{tabular}

The findings revealed that most of the ectenic learners in this study were field dependent, field insensitive, sharpener, particular, analytic, impulsive, sequential and deductive. Table (2) below indicates that the majority of accepted candidates at ILI recruitment test were synoptic learners. The learners' scores are distributed mostly between 30 to 60 and signifies that they have achieved very low scores even though they all were academically educated in English majors from universities. 
Table2. Teaching candidates accepted at iran language institute

\begin{tabular}{|c|c|c|c|c|c|c|c|c|c|c|c|c|c|c|c|c|c|c|c|c|c|c|c|c|c|}
\hline \multirow{2}{*}{$\begin{array}{l}\underset{G}{Z} \\
\stackrel{\Xi}{\sigma} \\
\stackrel{\sigma}{\Phi}\end{array}$} & \multicolumn{23}{|c|}{ Learning Styles } & \multirow{2}{*}{ 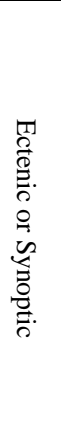 } & \\
\hline & 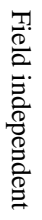 & 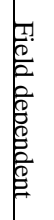 & 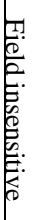 & 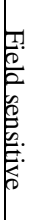 & 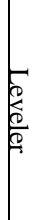 & 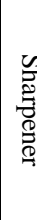 & 㟒 & 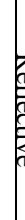 & & $\frac{a}{0}$ & 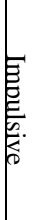 & : & $\begin{array}{l}\stackrel{\circlearrowright}{\Xi} \\
\stackrel{\Xi}{\Xi}\end{array}$ & & & 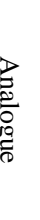 & 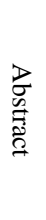 & $\begin{array}{l}\Omega \\
ٍ \\
\overparen{0} \\
\frac{0}{0}\end{array}$ & 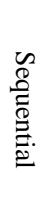 & $\begin{array}{l}\pi \\
\hat{0} \\
0 \\
0 \\
\Xi\end{array}$ & 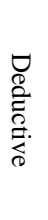 & 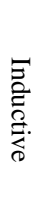 & 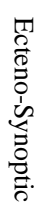 & & $\begin{array}{l}\mathscr{2} \\
\delta \\
\varnothing \\
\infty\end{array}$ \\
\hline 1 & 0 & & & 0 & & 0 & 0 & & & & 0 & & ( & & & & & 0 & & 0 & 0 & & 6 & $S$ & 80 \\
\hline 2 & & 0 & & 0 & & 0 & & & 0 & 0 & & 0 & & & & 0 & 0 & & & 0 & & 0 & 7 & S & 82 \\
\hline 3 & 0 & & & 0 & & 0 & & & 0 & 0 & & 0 & & & & 0 & & 0 & 0 & & 0 & & 5 & ES & 75 \\
\hline 4 & 0 & & & 0 & & 0 & & & 0 & 0 & & 0 & & & & 0 & & 0 & 0 & & & 0 & 6 & S & 80 \\
\hline 5 & 0 & & & 0 & & 0 & & & 0 & 0 & & 0 & & & & 0 & & 0 & & 0 & & 0 & 7 & $\mathrm{~S}$ & 80 \\
\hline 6 & 0 & & & 0 & & 0 & & & 0 & 0 & & & ( & & & 0 & & 0 & & 0 & & 0 & 8 & S & 85 \\
\hline 7 & 0 & & 0 & & 0 & & 0 & & 0 & & & 0 & & & & 0 & & 0 & & 0 & & 0 & 5 & ES & 75 \\
\hline 8 & 0 & & & 0 & & 0 & & & 0 & 0 & & 0 & & & & & & 0 & & 0 & & 0 & 6 & S & 80 \\
\hline 9 & 0 & & & 0 & & 0 & & & 0 & 0 & & 0 & & & & 0 & 0 & & & 0 & & 0 & 7 & $\mathrm{~S}$ & 80 \\
\hline 10 & 0 & & 0 & & & 0 & & & 0 & & 0 & 0 & & & & & & 0 & 0 & & 0 & & 4 & E & 70 \\
\hline 11 & 0 & 0 & 0 & & 0 & & 0 & & 0 & & & 0 & & & & 0 & & 0 & & 0 & & 0 & 5 & ES & 90 \\
\hline 12 & 0 & & & 0 & & 0 & & & 0 & 0 & & 0 & & & & 0 & 0 & & & 0 & & 0 & 7 & $\mathrm{~S}$ & 80 \\
\hline 13 & 0 & & 0 & & & 0 & 0 & & 0 & & & 0 & & & & 0 & 0 & & 0 & & 0 & & 3 & E & 70 \\
\hline 14 & 0 & & & 0 & 0 & & & & & 0 & 0 & & ( & & & 0 & & 0 & & 0 & 0 & & 6 & S & 80 \\
\hline 15 & 0 & & & 0 & & 0 & & & 0 & 0 & & & ( & & & 0 & & 0 & & 0 & & 0 & 8 & $S$ & 90 \\
\hline
\end{tabular}

The findings showed that only one of the accepted candidates was an ectenic learner and two of them were ecteno-synoptic. The findings revealed that most of the successful candidates at the reading section were field independent, field sensitive, sharpener, reflective, global, analogue, concrete, analytic and inductive. The most common learning styles among accepted and failed candidates were the sharpener and analytic style. In order to find correlations between the ecteno-synoptic range and the reading scores achieved on the recruitment examination, a test of Pearson Correlation Coefficient was performed and the results presented below were achieved. 
Scatter plot of failed candidates' ecteno-synoptic range and reading scores

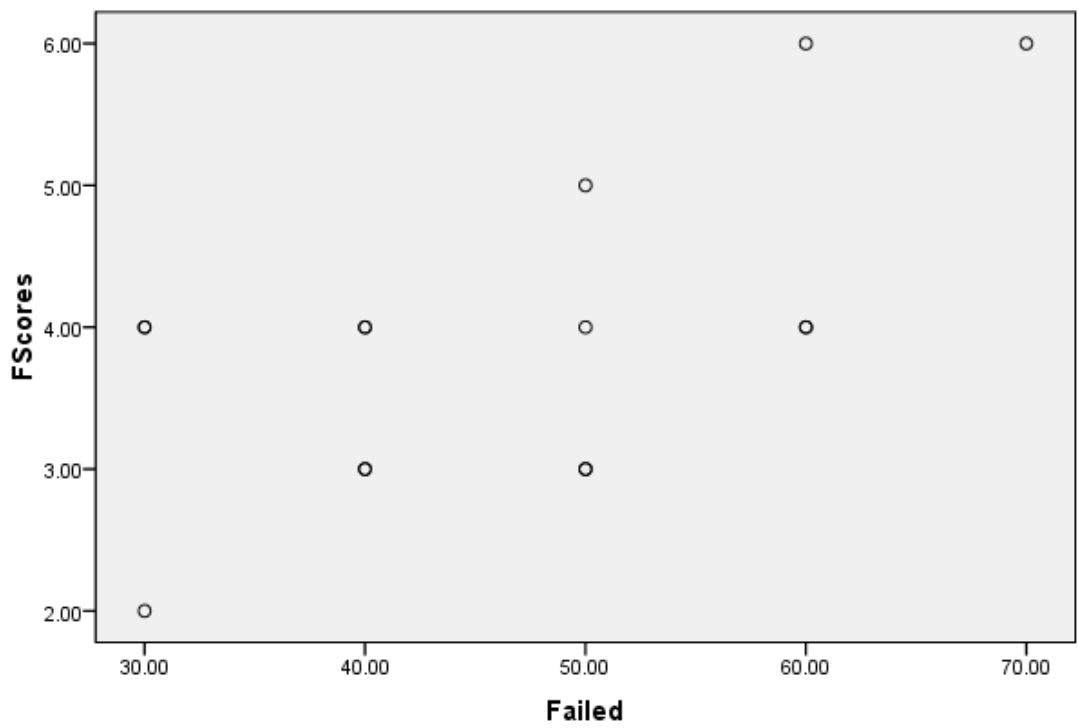

Figure 1. Scatter plot of failed candidates' ecteno-synoptic range and reading scores

The value of $\mathrm{R}$ is 0.6138 . This is a moderate positive correlation, which means candidates with high ecteno-synoptic scores tended to have higher reading scores on the test and those with low ecento-synoptic scores tended to have lower scores on the test. The value of R2, the coefficient of determination, is 0.3768 . Most of low score achievers were ectenic learners who had ecteno-synoptic scores lower than five.

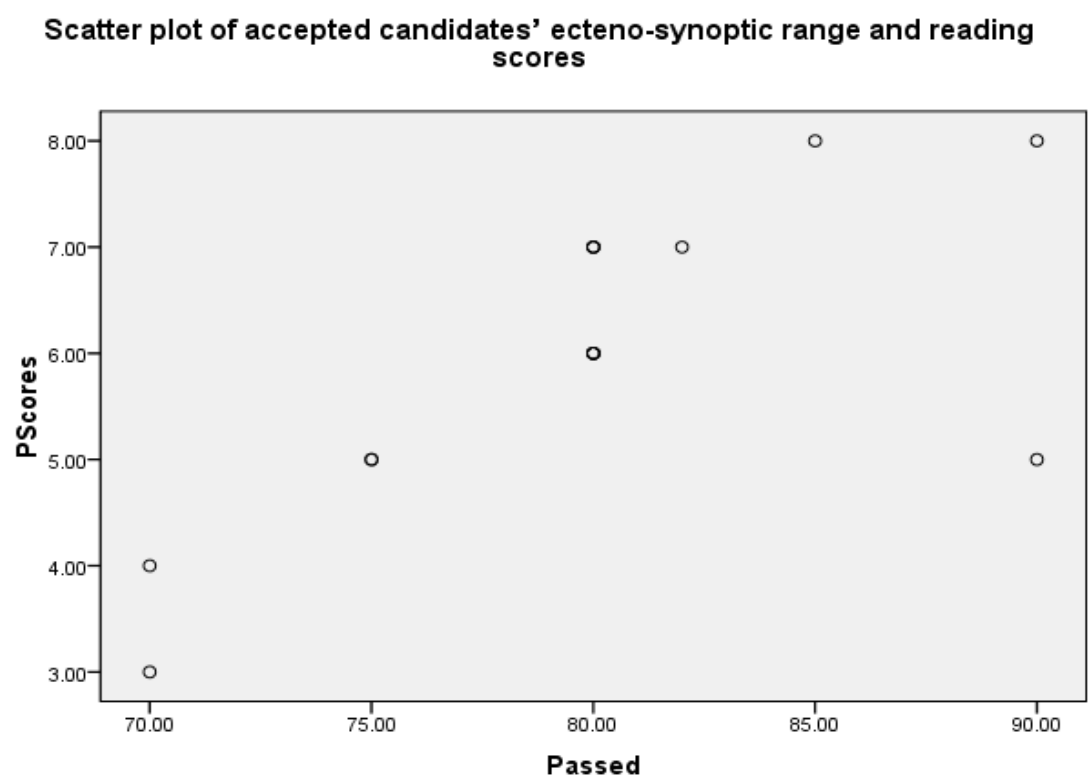

Figure2. Scatter plot of accepted candidates' ecteno-synoptic range and reading scores 


\section{NI Macrothink}

Global Journal of Educational Studies

ISSN 2377-3936

2017, Vol. 3, No. 2

The value of $\mathrm{R}$ is 0.708499 . This is a moderate positive correlation, which means candidates with high ecteno-synoptic scores ended to have higher reading scores and those with low ecento-synoptic scores tended to have lower reading scores on the test.The value of $\mathrm{R} 2$, the coefficient of determination, is 0.4780 . Most of high score achievers on the reading task were synoptic learners who had ecteno-synoptic scores higher than 5.

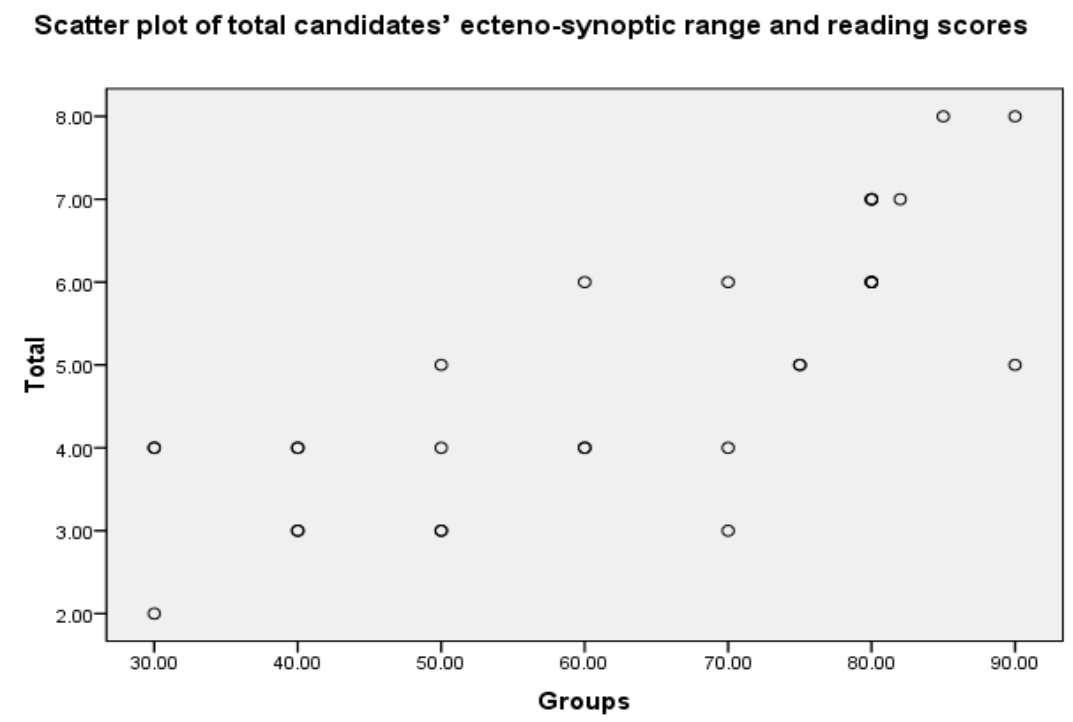

Figure 3. Scatter plot of total candidates' ecteno-synoptic range and reading scores

The value of $\mathrm{R}$ is 0.7795 . This is a strong positive correlation, which means candidates with high ecteno-synoptic scores tended to have higher reading scores and those with low ecteno-synoptic scores tended to have lower scores on the test as well. The value of $\mathrm{R} 2$, the coefficient of determination, is 0.6172 . The results assert the existence of high correlation between specific learning styles and the high reading proficiency on teaching recruitment examination.

\section{Conclusions and Discussions}

The results obtained in this study indicated that there was a high positive correlation between candidates' learning styles and their reading scores. These results also suggested that synoptic learners were more successful on Iran Language Institute's recruitment qualification. It is concluded from the results that some learning styles were conspicuously apparent among unsuccessful candidates; they were field dependent, field insensitive, sharpener, particular, analytic, impulsive, sequential and deductive learners. And the most highlighted learning styles attributed to the successful candidates included being field dependent, field sensitive, sharpener, reflective, global, analogue, concrete, analytic and inductive. Specific learning styles might be grouped together and be the exemplar of successful learners and candidates on performing well on reading tasks in Iran.

Actually each student has particular performance in language skills that persuade Naiman et 
al. (1978) to emphasize on the concept "Good Language learner "to exhibit student's attributes contributing to successful language learning. It is inferred from the findings that teaching in accordance with the learners' typical learning styles would help them in developing their language skills and support them through their performance on the reading tasks. Teaching in line with the learners' preferences and styles also consolidates the findings by Khoshsima and Banaruee (2017) who declared that all of the students have personal characteristics associated with their learning processes and they may indicate the type of errors learners confront in the learning process. However, Kilic and Karadeniz's (2004) indicated that students' success did not change with gender, learning style and navigation strategies. The current study's findings were in contrast with such findings as not only the effect of having a typical learning style indicated the level of learners' proficiency in reading but also revealed their success in academic settings.

Such findings represented that it is highly beneficial to make students aware of their learning style differences and the changes it will bring to their academic achievements. Teachers may also be encouraged to modify their teaching styles to best fit the needs of their students according to their learning styles. The results also confirmed the findings from Zare-Behtash, Khatinzadeh and Banaruee's (2017) study that various teaching methodologies must be employed in language classes particularly in ESP courses as reading is the most fundamental material in ESP courses in Iran. It should be taken into account that learning style is just one of the many factors which influence the learning process and the learning results (Castro \& Peck, 2005). The aim of this study in investigating the correlation between learning style and the reading performance was not to determine the superiority of one learning style to another. Yet, the information was invaluable in providing teachers, learners and curriculum designers with new insight into how to verify their teaching approaches and how to help learners to be aware of their own capabilities in learning through achievement.

\section{Acknowledgement}

The authors express their gratitude to Dr. Fernando Marmolejo-Ramos for proofreading this article and to Mr. Mohammad Na'eem Shafi'ee-Poor for his cooperation at Iran Language Institute on the collection of data. The authors also express their gratitude to Mr. Ali Banaruee and Hassan Askari for their constant support.

\section{References}

Banaruee, H. (2016). Recast in Writing. Sana Gostar Publications.

Banaruee, H., \& Askari, A. (2016). Typology of Corrective Feedback and Error Analysis. Sana Gostar Publications.

Banaruee, H., Khoshsima, H., \& Askari, A. (2017). Corrective Feedback and Personality Type: a case study of Iranian L2 learners. Global Journal of Educational Studies, 3(2), 14-21, https://doi.org/10.5296/gjes.v3i2.11501

Banaruee, H., Mohammadian, A., \& Zare-Behtash, E. (2017). Metadiscourse Markers in Pure Mathematics Textbooks. Global Journal of Educational Studies, 3(2), 62-69. 
https://doi.org/10.5296/gjes.v3i2.11796

Castro, O., \& Peck, V. (2005). Learning styles and foreign language learning difficulties. Foreign Language Annuals, 38, 401-409. https://doi.org/10.1111/j.1944-9720.2005.tb02226.x

Dorneyei, Z., \& Skehnan, P. (2005). Individual Differences in Second Language Learning, in C. J. Doughty, and M. H. Long (Eds.), The Handbook of Second Language Acquisition (pp. 256-310). United Kingdom: Blackwell Publishing.

Ehrman, M. E., Leaver, B. L., \& Oxford, R. L. (2003). A brief overview of individual differences in second language learning. System, 31, 313-330. https://doi.org/10.1016/S0346-251X(03)00045-9

Ehrman, M., \& Oxford, R. (1990). Adult language learning styles and strategies in an intensive training setting. Modern Language Journal, 74, 311-326. https://doi.org/10.1111/j.1540-4781.1990.tb01069.x

Felder, R. M. (2010). Are learning styles invalid? (Hint: No!). On-Course Newsletter (pp. $1-7)$.

Khatin-Zadeh, O., Bakhshizadeh Gasht, Y., \& Banaruee, H. (2017). Partial vs. Full Abstract Classes: A Review of Glucksberg's Class-Inclusion Model of Metaphor Comprehension, International Journal of Brain and Cognitive Sciences, 6(3), 51-57. https://doi.org/10.5923/j.ijbcs.20170603.02

Khoshsima, H., \& Banaruee, H. (2017). L1 Interfering and L2 Developmental Writing Errors among Iranian EFL Learners, European Journal of English Language Teaching, 2(4), 1-14. https://doi.org/10.5281/zenodo.802945

Kilıç, E., \& Karadeniz, Ş. (2004). Cinsiyet ve Öğrenme Stilinin Gezinme Stratejisi ve Başarıya Etkisi. Gazi Üniversitesi Gazi Eğitim Fakültesi Dergisi, 24(3), 129-146.

Kolb, A., \& Kolb, D. (2005). The Kolb Learning Style Inventory. Version 3, 2005. Technical Specifications.

Li, J., \& Qin, X. Q. (2006). Language learning styles and strategies of tertiary-level English learners in China. RELC Journal, 37(1), 67-89. https://doi.org/10.1177/0033688206063475

Naiman, N., Frohlich, M., Stern, H. H., \& Todesco, A. (1978). The good language learner: Research in Education (pp. 285-288). Toronto, Ontario, Canada: Institute for Studies in Education.

Pask, G. (1988). Learning strategies, teaching strategies, and conceptual or learning style. In R. R. Schmeck (Ed.), Learning Strategies and learning styles (p. 83). New York. https://doi.org/10.1007/978-1-4899-2118-5_4

Zare-Behtash, E., \& Banaruee, H. (2017). Critical Evaluation of the New Headway Advanced and the ILI Advanced Series: A Comparison of Curricular Components and CLT Objectives Based on ACTFL. International Journal of Applied Linguistics \& English Literature. https://doi.org/10.7575/aiac.ijalel.v.6n.5p.182 
Zare-Behtash, E., Bakhshizadeh Gashti, Y., Khatinzadeh, O., \& Banaruee, H. (2017). Personality Type and Performance on Listening Tests: A Study of Correlation between Personality Traits and Performance on "Listening for Gist" and "Minimal Pairs". International Journal of Psychology and Behavioral Sciences, 7(5), 123-126. https://doi.org/10.5923/j.ijpbs.20170705.01

Zare-Behtash, E., Khatinzadeh, O., \& Banaruee, H. (2017). A Comparative Study of Teaching Methods in ESP Courses. European Journal of English Language Teaching, 2(3), 39-49. https://doi.org/10.5281/zenodo.802937

Zin, N. A., Zaman, H. B., \& Noah, S. A. (2002). Multimedia Mathematics Tutor: Matching Instruction to Student's Learning Styles. ICCE, 1433. https://doi.org/10.1109/CIE.2002.1186283

\section{Copyright Disclaimer}

Copyright for this article is retained by the author(s), with first publication rights granted to the journal.

This is an open-access article distributed under the terms and conditions of the Creative Commons Attribution license (http://creativecommons.org/licenses/by/3.0/). 